Original Article

\title{
A Novel Method to Estimate the Contribution of the Vapor Activity of Essential Oils in Agar Diffusion Assay
}

\author{
Shigeharu Inouye ${ }^{1}$, Katsuhisa Uchida ${ }^{2}$, Naho Maruyama ${ }^{1}$, \\ Hideyo Yamaguchi ${ }^{1,2}$, Shigeru Abe ${ }^{1}$ \\ ${ }^{1}$ Teikyo University Institute of Medical Mycology, \\ 359 Otsuka, Hachioji, Tokyo 192-0395, Japan \\ ${ }^{2}$ Teikyo Association of Medical Mycology, \\ 359 Otsuka, Hachioji, Tokyo 192-0395, Japan
}

[Received: 15, August 2005. Accepted: 20, January 2006]

\begin{abstract}
By the combined use of agar diffusion, agar vapor and agar vapor-inhibitory assays, contribution of the vapor activity of essential oils was quantitatively estimated. The test organisms were Trichophyton mentagrophytes and Aspergillus fumigatus. Agar vapor assay was used to confirm the vapor activity of the oils. The parameter delta defined as a contribution index of the vapor activity was calculated by $(1-\mathrm{b}-\mathrm{c} / \mathrm{a}-\mathrm{c}) \times 100$, where $\mathrm{a}$ is inhibitory diameter in the diffusion assay, $\mathrm{b}$ is inhibitory diameter in the vapor-inhibitory assay and $\mathrm{c}$ is diameter of the sealed ring in the vaporinhibitory assay $(21 \mathrm{~mm})$. Many of the essential oils examined showed a delta value near 100, thus providing the major contribution of the vapor activity to the inhibitory diameter. Essential oils containing aldehyde as major constituent showed low delta value, indicating the major inhibition was due to agar diffusion. Major essential oil components behaved similarly; the delta value was increased in the following order: aldehyde $<$ phenol $<$ alcohol $<$ ester, oxide, hydrocarbon, indicating the enhanced contribution of the vapor activity in that order.
\end{abstract}

Key words: essential oil, vapor activity, Trichophyton mentagrophytes, Aspergillus fumigatus, agar diffusion assay, agar vapor assay, agar vapor-inhibitory assay

\section{Introduction}

Essential oils have been known to show inhibition of proliferation or killing activity against a wide variety of microorganisms including viruses, mycoplasma and chlamydia, bacteria, fungi, protozoans and harmful insects such as mites ${ }^{1)}$. Essential oils are currently attracting much attention because they showed activity against antibiotic-resistant pathogens such as methicillin-resistant Staphylococcus aureus (MRSA), penicillin-resistant Streptococcus pneumoniae (PRSP), vancomycin-resistant Enterococcus faecium (VRE) and fluconazole and itraconazole-resistant Candida sp. ${ }^{2-5)}$.

The agar diffusion assay which is often called an aromatogram in aromatherapy ${ }^{1)}$, is the most

\footnotetext{
Address correspondence to: Shigeharu Inouye

Teikyo University Institute of Medical Mycology

359 Otsuka, Hachioji, Tokyo 192-0395, Japan
}

widely spread technique of antimicrobial activity assessment of essential oils ${ }^{6)}$. Chao et al. ${ }^{7)}$ evaluated the antimicrobial activity of 45 essential oils on 8 bacteria and 3 fungi using the agar diffusion assay. However, Kubo et al. ${ }^{8)}$ stated that the diffusion method was inappropriate for essential oils as poorly soluble compounds did not diffuse well in the agar medium. Griffin et $a l .{ }^{9)}$ mentioned that the water-insoluble components of oils either remained on the disc or evaporated and only water-soluble components diffused in the agar from the disc, leading to underestimation of the activity of the oils.

However, we have observed that some oils showed overall inhibition throughout a petri dish in the agar diffusion assay. As the hydrophobic nature of most oils prevented the uniform diffusion of the constituents through the agar medium, the enlarged zone was suggested to be due to vaporization of the oils followed by 
their redeposition on the agar. We have already reported that the MIC values of essential oils were decreased by sealing, indicating the effect of vaporization on the activity ${ }^{10)}$. Furthermore, essential oils inhibited the growth of bacteria ${ }^{11}$ ) and fungi ${ }^{12,13)}$ by the vapor state. Therefore, contribution of the vapor activity (antimicrobial activity in the vapor state) in the agar diffusion assay was reasonably assumed, but the evidence was lacking.

The purpose of this paper was to prove the contribution of the vapor activity in the agar diffusion assay, which was closely related with the validity of this method for the determination of the antimicrobial activity of essential oils. For this purpose, we have developed a convenient method to estimate the vapor activity of the oils by the combined use of agar diffusion, agar vapor and agar vapor-inhibiting assays. The agar vapor assay was used to confirm the vapor activity. The last assay was newly developed in this laboratory to detect the activity due to diffusion alone through agar by inhibiting the vaporization. The inhibition of vaporization was accomplished by sealing the disc containing essential oil with a plastic sealed ring. For the application of this method, a large inhibitory diameter exceeding the size of the sealed ring was necessary. We have screened the test organisms using Escherichia coli, Staphylococcus aureus, Candida albicans, Aspergillus fumigatus and Trichophyton mentagrophytes, and found that $A$. fumigatus and especially T. mentagrophytes were highly susceptible to essential oils showing a large inhibitory diameter. By comparing the inhibitory diameters of agar diffusion and agar vapor-inhibitory assays, it became possible to calculate semi-quantitatively the contribution of the vapor activity of the oils.

The second purpose of this study was to correlate the antifungal activity of the oils determined by the agar diffusion assay with that of the major constituents of the respective oils. So far, no comparative study has been reported on the anti-Trichophyton activity of a large number of the oils. Accordingly, we have estimated the contribution of the vapor activity of a variety of essential oils and their major constituents in agar diffusion assay including the new method.

\section{Materials and Methods}

Test organisms and culture media

T. mentagrophytes TIMM 2789 was a stock culture of Teikyo University Institute of Medical Mycology. Among many T. mentagrophytes and $T$. rubrum, we selected this strain because the formation of small conidia was highly reproducible after repeated cultivation. Aspergillus fumigatus IFM 41392 was from the Research Center for Pathogenic Fungi and Microbial Toxicoses, Chiba University, and has been used for evaluation of essential oils. Bacto ${ }^{\mathrm{TM}}$ Sabouraud Dextrose Agar, Bacto ${ }^{\mathrm{TM}}$ Pepton, and Bacto ${ }^{\mathrm{TM}}$ Agar were obtained from Becton Dickinson, France S.A., La Pont du Claix, France. Sabouraud agar was from bioMerieux, Marcy l'Etoile, France, agar medium from Eiken Kagaku Co., Tokyo and Agarose-1 from Dojin Kagaku Kenkyusho, Kumamoto. Glucose and $\mathrm{KH}_{2} \mathrm{PO}_{4}$ were from Wako Pure Chemical Industries, Ltd., Osaka. The composition of $1 / 10$ Sabouraud agar was $0.2 \%$ peptone, $0.1 \%$ glucose, $\quad 0.1 \% \quad \mathrm{KH}_{2} \mathrm{PO}_{4}, \quad 0.1 \% \quad \mathrm{MgSO}_{4} \cdot$ $7 \mathrm{H}_{2} \mathrm{O}$ and $0.1 \%$ agar.

\section{Essential oils, major constituents and other chemicals \\ Essential oils were obtained from Sanoflore,} France, through Hyper Plants Co. Ltd., Tokyo unless otherwise stated. Cinnamon bark and thyme thymol oils were from La Florina, Germany via Ten No Kaori, Tokyo, perilla oil and perillaldehyde from Kohken Koryo, Yokohama. Coriander, thyme thujanol and thyme geraniol oils were obtained from Pranarom International S.A., Belgium via Kenso Igakusha, Ltd. Yamanashi. Santolina and tansy oils were prepared in Nagatoro, Saitama, Japan by cultivation of the parent plants (Santolina chamaecyparissus and Tanacetum vulgare) followed by steam distillation. The composition of essential oils used was analyzed by gas-chromatography/mass spectroscopy (data not shown). Carene oxide, carene and limonene were from Nippon Terpene Co., Kobe. Other major components of the oils and Tween 80 were from Tokyo Kasei Kogyo Co., Tokyo. Tolnaftate was stocked in this laboratory.

\section{Fungal inocula and assay media}

T. mentagrophytes and A. fumigatus were precultured on 1/10 Sabouraud agar slant and Sabouraud dextrose (Difco) agar slant at $27^{\circ} \mathrm{C}$ for 2 weeks and 3 days, respectively. Conidia were taken from the slants using sterile saline containing $0.05 \%$ Tween 80. Mycelia were removed by filtration through gauze, and the filtrate was adjusted to $1 \times 10^{8}$ conidia/ml using a microscope. One $\mathrm{m} l$ of this conidial suspension was added to $100 \mathrm{ml}$ of agar medium containing $1 \%$ peptone, $1 \%$ glucose, $1 \%$ Agarose- 1 at $50^{\circ} \mathrm{C}$, and the mixture $(3 \mathrm{ml})$ was overlaid on the surface of hardened Sabouraud 
dextrose agar $(15 \mathrm{~m} l)$ in a petri dish $(80 \mathrm{~mm}$ in diameter, Eiken Kizai, Tokyo) to prepare a double-layered agar medium.

\section{Agar diffusion assay}

The agar assay was carried out by putting 30 $\mu l$ of a pure oil or an ethyl acetate solution of an oil on a paper disc $(8 \mathrm{~mm}$ in diameter, Advantec, Toyo Roshi Kaisha, Ltd., Tokyo) followed by air drying at room temperature for $10 \mathrm{~min}$. The disc was placed on the center of the double-layered agar medium in a petri dish, sealed with vinyl tape and incubated at $27^{\circ} \mathrm{C}$ for 2 days for $A$. fumigatus and 4 days for $T$. mentagrophytes. A conidium-inhibitory zone was observed after 3 days cultivation (A. fumigatus). An inhibitory diameter was measured by means of a slide caliper. All the assays were done in triplicate, and the mean values and standard deviation (SD) were recorded. When no growth occurred on the entire area of the dish, the inhibitory zone was recorded as $>80 \mathrm{~mm}$, which was the inside diameter of the petri dish.

\section{Agar vapor assay}

The vapor activity of essential oils was determined according to the literature ${ }^{14)}$ with slight modification. A paper disc containing 30 $\mu l$ of a test sample was fixed using a stapler at the center of a paper filter $(75 \mathrm{~mm}$ in diameter), which was placed inside the upper lid of the dish. Droplets of water were put around the perimeter of the filter paper to fix the paper on the lid. The petri dish containing the double-layered agar medium was inverted and placed on the upper lid containing the filter paper. The surface of the disc was at a distance of about $4 \mathrm{~mm}$ from the growth surface of the test organism. The dish was sealed with vinyl tape and was incubated as described above, and the diameter of the inhibition zone was determined.

\section{Agar vapor-inhibitory assay}

A paper disc containing essential oil was placed on the double-layered agar medium, and sealed with a plastic sealed ring (15, 21 or $24 \mathrm{~mm}$ in diameter, Ring Clear, Tokyu Hands, Tokyo), one side of which was closed with a micro cover glass $(24 \times 24 \mathrm{~mm}$, Matsumami Glass Ind., Ltd., Tokyo) using a plastic cement (Epo, Semedain, Ltd., Tokyo). The open side of the plastic ring touched the surface of the double-layered agar medium. Because of its light weight, sinking was kept to a minimum to guarantee the free diffusion through the agar

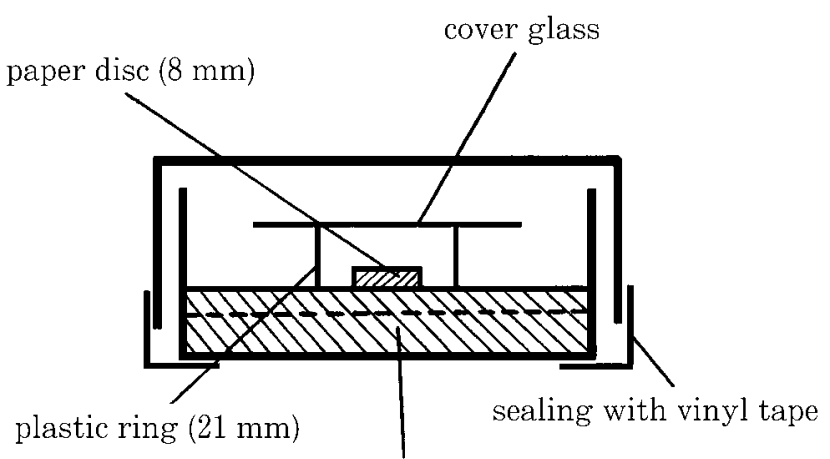

agar medium inoculated with conidia (double layer)

Fig. 1. Schematic presentation of the agar vapor-inhibitory assay.

layer. After a preliminary experiment, a ring 21 $\mathrm{mm}$ in size was adopted, since an unusually large inhibition zone was occasionally observed when a $15 \mathrm{~mm}$ ring was used. On the other hand, no significant difference was observed between rings of 21 and $24 \mathrm{~mm}$ (Fig. 1). After sealing and incubation, the diameter of the inhibitory zone was measured as described above.

\section{Results and Discussion}

Table 1 compares the growth-inhibitory diameters of 24 essential oils against T. mentagrophytes in the agar diffusion, vapor and vapor-inhibitory assays. Fig. 2 shows the growth-inhibitory pattern of $5 \%$ thyme thymol oil (I) in three assays. With several exceptions, the SD was largest in the agar vapor assay. The deviation was moderate in agar diffusion assay, and least in the agar vapor-inhibitory assay. Most of the essential oils examined showed a similar inhibition zone by both agar diffusion and vapor assays, indicating that these oils showed the vapor activity.

To determine contribution of the vapor activity on the inhibitory diameter in the agar diffusion assay, we set up a delta value defined by the equation, $\delta=(1-\mathrm{b}-\mathrm{c} / \mathrm{a}-\mathrm{c}) \times 100$, where $\mathrm{a}$ is the inhibitory diameter in the diffusion assay, and $b$ and $c$ are inhibitory diameter and outer diameter of the sealed ring in the vapor-inhibitory assay. The delta value showed a maximum around 100 when the vapor contribution was dominant, and showed a minimum around 0 when the diffusion was dominant under an ideal condition. Thus, the delta value may be used as a measure of contribution of vapor and diffusion to the inhibitory diameter in the agar diffusion assay. We defined the delta value of $100 \sim 70$ to indicate the major contribution of the vapor activity, and the value of $0 \sim 30$ to indicate the major contribution of the diffusion. 
A value between $31 \sim 69$ was suggestive for a mixed contribution from vapor and diffusion. Non-volatile tolnaftate showed the delta value of 13 .

As judged from the delta values in Table 1, 10 oils (thyme thymol, coriander, geranium Bourbon, lavender, palmarosa, tea tree, thyme geraniol, santolina, rosewood and nutmeg) showed a major contribution of the vapor activity, but 3 oils (cinnamon bark, lemongrass and melissa) showed the main contribution from agar diffusion. Clove oil was intermediate. The oils showing a diameter of less than 26 $\mathrm{mm}$ in the agar diffusion assay were omitted from the calculation, considering the deviation of the measurement. The delta value could not be determined on perilla, oregano, citronella, sandalwood, thyme thujanol, tansy, ravensara, frankincense, galbanum or myrrh oils. An increase of concentration resulted in overall inhibition of the petri dish in cases of oregano, coriander, lavender, rosewood, tea tree and tansy. When these oils (perilla, coriander, rosewood, sandalwood, thyme thujanol, tansy, ravensara frankincense and myrrh) showed smaller diameter than the size of the ring $(21 \mathrm{~mm})$ in the agar diffusion assay, they exhibited an inhibitory diameter of $21 \mathrm{~mm}$ within the sealed ring. This might have been caused by sealing of the vapor in the small space (21 $\mathrm{mm}$ diameter) resulting

Table 1. Growth-inhibitory diameters of 24 essential oils in the agar diffusion, agar vapor and agar vapor-inhibitory assays against T. mentagrophytes

\begin{tabular}{|c|c|c|c|c|c|}
\hline \multirow{2}{*}{\multicolumn{2}{|c|}{ Major component Essential oil }} & \multicolumn{4}{|c|}{ Inhibitory diameter (mm) } \\
\hline & & \multirow{2}{*}{$\begin{array}{c}\text { Diffusion assay } \\
58 \pm 2 * *\end{array}$} & \multirow{2}{*}{$\begin{array}{c}\text { Vapor assay } \\
61 \pm 5\end{array}$} & \multirow{2}{*}{$\begin{array}{c}\text { Vapor-inhibitory assay } \\
53 \pm 3\end{array}$} & \multirow{2}{*}{$\frac{\delta \text { value }}{14}$} \\
\hline Aldehyde & Cinnamon bark (1\%) & & & & \\
\hline & Lemongrass（1\%） & $28 \pm 3$ & $38 \pm 6$ & $26 \pm 2$ & 29 \\
\hline & Melissa $(5 \%)$ & $31 \pm 6$ & $26 \pm 4$ & $29 \pm 3$ & 20 \\
\hline & Perilla $(1 \%)$ & $13 \pm 1$ & $17 \pm 2$ & $21 \pm 0$ & \\
\hline \multirow[t]{3}{*}{ Phenol } & Clove $(5 \%)$ & $48 \pm 5$ & $50 \pm 8$ & $34 \pm 3$ & 52 \\
\hline & Oregano $(5 \%)$ & $>80$ & $73 \pm 6$ & $60 \pm 7$ & \\
\hline & Thyme thymol $(5 \%)$ & $61 \pm 6$ & $65 \pm 12$ & $27 \pm 2$ & 87 \\
\hline \multirow[t]{9}{*}{ Alcohol } & Citronella $(5 \%)$ & $25 \pm 3$ & $25 \pm 3$ & $22 \pm 1$ & \\
\hline & Coriander $(10 \%)$ & $>80$ & $>80$ & $27 \pm 3$ & $>90$ \\
\hline & Coriander $(5 \%)$ & $11 \pm 1$ & spur & $21 \pm 0$ & \\
\hline & Geranium Bourbon (5\%) & $55 \pm 4$ & $56 \pm 3$ & $24 \pm 2$ & 91 \\
\hline & Lavender $(100 \%)$ & $>80$ & $>80$ & $63 \pm 10$ & \\
\hline & Lavender $(10 \%)$ & $33 \pm 5$ & $36 \pm 6$ & $22 \pm 1$ & 92 \\
\hline & Palmarosa $(5 \%)$ & $64 \pm 3$ & $79 \pm 7$ & $24 \pm 2$ & 93 \\
\hline & Rosewood $(10 \%)$ & $>80$ & $>80$ & $34 \pm 2$ & $>78$ \\
\hline & Rosewood (5\%) & $16 \pm 3$ & $20 \pm 4$ & $21 \pm 0$ & \\
\hline \multirow[t]{6}{*}{ Alcohol } & Sandalwood $(10 \%)$ & $18 \pm 2$ & $35 \pm 4$ & $21 \pm 0$ & \\
\hline & Tea tree $(100 \%)$ & $>80$ & $>80$ & $48 \pm 9$ & \\
\hline & Tea tree $(10 \%)$ & $33 \pm 2$ & $40 \pm 5$ & $22 \pm 1$ & 92 \\
\hline & Thyme geraniol $(10 \%)$ & $54 \pm 4$ & $58 \pm 6$ & $23 \pm 1$ & 94 \\
\hline & Thyme geraniol (5\%) & $27 \pm 2$ & $54 \pm 8$ & $21 \pm 1$ & 100 \\
\hline & Thyme thujanol $(5 \%)$ & $16 \pm 2$ & $15 \pm 2$ & $21 \pm 0$ & \\
\hline Ketone & Santolina $(5 \%)$ & $31 \pm 4$ & $41 \pm 7$ & $23 \pm 1$ & 80 \\
\hline \multirow[t]{2}{*}{ Ester } & Tansy $(100 \%)$ & $>80$ & $>80$ & $43 \pm 6$ & $>63$ \\
\hline & Tansy $(10 \%)$ & $13 \pm 1$ & $19 \pm 2$ & $22 \pm 1$ & \\
\hline Oxide & Ravensara $(10 \%)$ & $10 \pm 0$ & $9 \pm 1$ & $21 \pm 0$ & \\
\hline \multirow[t]{4}{*}{ Hydrocarbon } & Frankincense $(10 \%)$ & $13 \pm 1$ & $10 \pm 1$ & $21 \pm 0$ & \\
\hline & Galbanum (5\%) & $24 \pm 1$ & $23 \pm 2$ & $21 \pm 0$ & \\
\hline & Myrrh $(10 \%)$ & $17 \pm 2$ & $12 \pm 1$ & $21 \pm 0$ & \\
\hline & Nutmeg $(5 \%)$ & $30 \pm 1$ & $29 \pm 4$ & $21 \pm 0$ & 100 \\
\hline Control & Tolnaftate $(0.01 \%)$ & $36 \pm 4$ & not detected & $34 \pm 2$ & 13 \\
\hline
\end{tabular}

$*$ delta $=\{1-(\mathrm{b}-21 / \mathrm{a}-21)\} \times 100$, where $a$ is an inhibitory diameter in the diffusion assay, $b$ is an inhibitory diameter in the vapor-inhibitory assay. A delta value $(70 \sim 100)$ indicated the major contribution from vapor, delta (31 69) mixed contribution from vapor and diffusion, delta ( $0 \sim 30)$ major contribution from agar diffusion. A delta value was calculated on oils that showed inhibitory diameter above $26 \mathrm{~mm}$ in the agar diffusion assay.

**An inhibitory diameter was an average \pm standard deviation $(n=3)$. A diameter in the agar diffusion and agar vapor-inhibitory assays included the diameter of paper disc. 
Table 2. Growth-inhibitory diameters of 15 major components of essential oils in the agar diffusion, agar vapor and agar vapor-inhibitory assays against T. mentagrophytes

\begin{tabular}{|c|c|c|c|c|c|}
\hline \multirow{2}{*}{ Function } & \multirow{2}{*}{ Essential oil } & \multicolumn{4}{|c|}{ Inhibitory diameter (mm) } \\
\hline & & Diffusion assay & Vapor assay & Vapor-inhibitory assay & $\delta$ value* \\
\hline \multirow[t]{3}{*}{ Aldehyde } & Cinnamaldehyde (1\%) & $56 \pm 4$ & $61 \pm 10$ & $51 \pm 3$ & 14 \\
\hline & Citral (1\%) & $60 \pm 5$ & $49 \pm 9$ & $41 \pm 2$ & 49 \\
\hline & Perillaldehyde (5\%) & $39 \pm 5$ & $42 \pm 5$ & $29 \pm 3$ & 56 \\
\hline \multirow[t]{2}{*}{ Phenol } & Eugenol（1\%） & $23 \pm 2$ & $25 \pm 2$ & $21 \pm 0$ & \\
\hline & Thymol (1\%) & $41 \pm 2$ & $37 \pm 9$ & $27 \pm 2$ & 70 \\
\hline \multirow[t]{4}{*}{ Alcohol } & Citronellol（5\%） & $68 \pm 5$ & $79 \pm 1$ & $32 \pm 3$ & 77 \\
\hline & Geraniol（5\%） & $44 \pm 6$ & $70 \pm 9$ & $29 \pm 1$ & 65 \\
\hline & Linalool $(5 \%)$ & $15 \pm 3$ & $15 \pm 4$ & $21 \pm 0$ & \\
\hline & Terpinen-4-ol（5\%） & $13 \pm 1$ & spur & $21 \pm 0$ & \\
\hline \multirow[t]{2}{*}{ Ester } & Linalyl acetate $(100 \%)$ & $>80$ & $>80$ & $21 \pm 0$ & 100 \\
\hline & Linalyl acetate $(10 \%)$ & $25 \pm 3$ & $11 \pm 0$ & $21 \pm 0$ & \\
\hline \multirow[t]{2}{*}{ Oxide } & Carene oxide (100\%) & $>80$ & $24 \pm 3$ & $21 \pm 0$ & 100 \\
\hline & Carene oxide $(10 \%)$ & $10 \pm 0$ & spur & $21 \pm 0$ & \\
\hline \multirow[t]{2}{*}{ Hydrocarbon } & 3-Carene $(100 \%)$ & $34 \pm 2$ & $38 \pm 6$ & $22 \pm 1$ & 92 \\
\hline & Limonene $(100 \%)$ & $53 \pm 3$ & $59 \pm 14$ & $26 \pm 3$ & 84 \\
\hline
\end{tabular}

For the calculation of delta value, see Table 1 footnote.
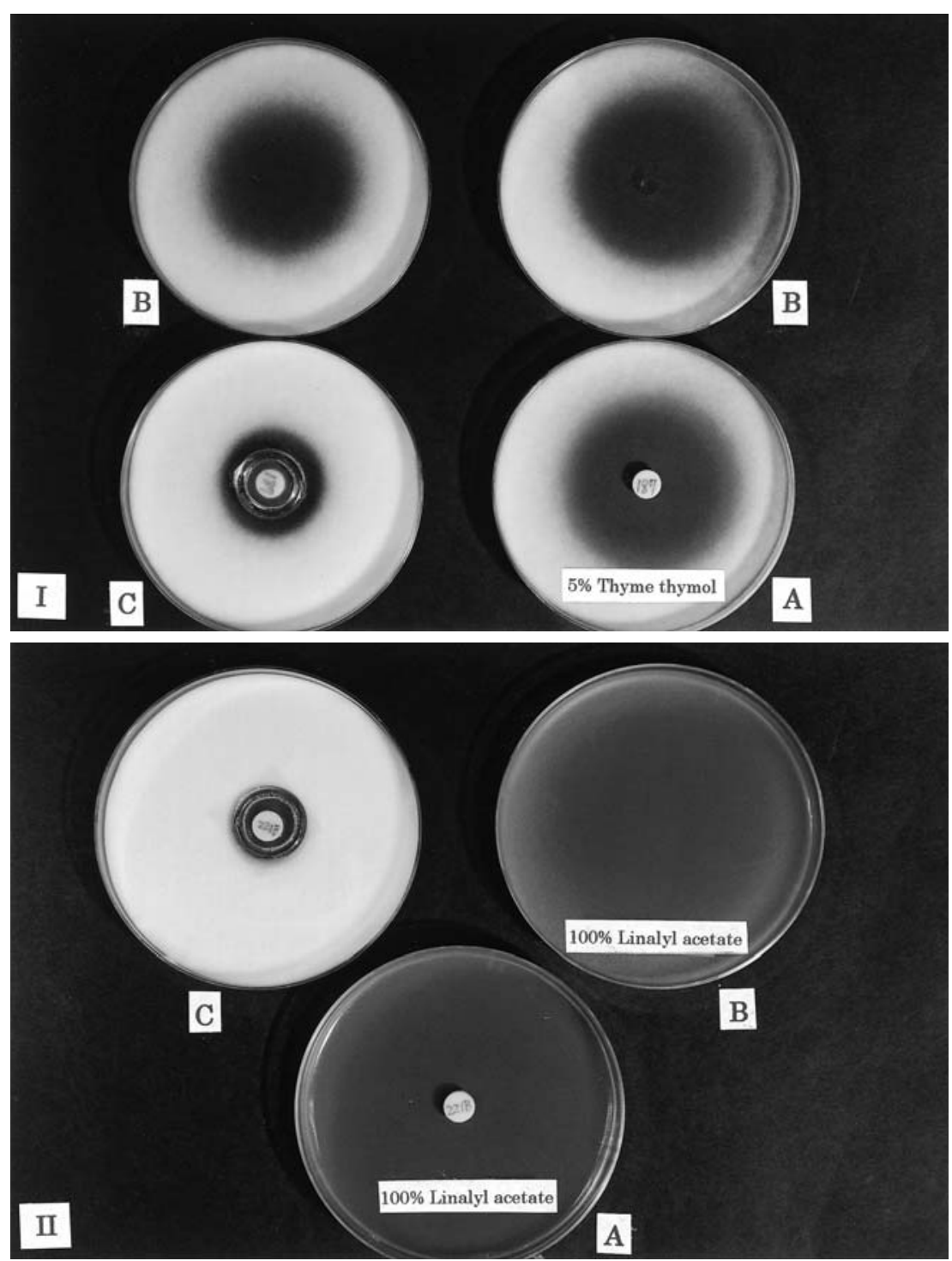

Fig. 2. Growth-inhibitory patterns of $5 \%$ thyme thymol (I) and $100 \%$ linalyl acetate (II) against T. mentagrophytes by the agar diffusion (A), agar vapor (B) and agar vapor-inhibitory (C) assays. 
in a local increase of gaseous concentration.

It was found that the oils containing alcohol, ketone, ester, oxide and hydrocarbon as major constituents exhibited dominant vapor activity, whereas the oils containing aldehyde group exhibited dominant diffusion activity. The oil containing phenol (clove oil) exhibited a mixed contribution of vapor and diffusion.

In order to confirm these tendencies, the 15 major constituents of the oils were examined and the delta values are shown in Table 2. As compared with ester (linalyl acetate), oxide (carene oxide) and hydrocarbon (3-carene, limonene) which showed high delta value, alcohol (geraniol, citronellol), phenol (thymol), and especially aldehyde (cinnamaldehyde, citral, perillaldehyde) components showed a lower value, indicating that the contribution from diffusion was increased. A delta value could not be obtained for eugenol, linalool or terpinen-4-ol.

Fig. 2 shows the inhibitory pattern of $100 \%$ linalyl acetate (II), in which overall inhibition over the petri dish was observed in agar diffusion and agar vapor assays. However, the inhibition remained within the sealed ring in the agar vapor-inhibitory assay, indicating that the inhibitory diameter in the agar diffusion assay was mostly due to the vapor activity. Complete inhibition over the entire area of the dish was observed after the definite threshold of concentration was exceeded, as typically shown by coriander, lavender, rosewood, tansy, tea tree, linalyl acetate and carene oxide. This was different from the anti-fungal agent, tolnaftate which showed a definite dose-response curve in the range of $0.0001 \sim 0.01 \%$, and no complete inhibition over the whole area in the dish. Complete inhibition by a high concentration of essential oils seemed to be characteristic of the vapor activity.

Table 3 shows the growth-inhibitory pattern of ten essential oil components against $A$. fumigatus. Since these components were less active against Aspergillus sp. than Trichophyton sp., many components were applied in a nondiluted state. The inhibitory diameters of these components by the agar vapor assay were comparable to those by the agar diffusion assay, but the diameters by the agar vapor-inhibitory assay were reduced. Except for linalyl acetate, a delta value was calculated. The value was increased from aldehyde (citral, perillaldehyde) to phenol (thymol), alcohol (linalool, terpinen4-ol, carene alcohol), ester- oxide-hydrocarbon (linalyl acetate, carene oxide, limonene and 3carene) in that order, similar to the order for $T$. mentagrophytes. This indicated that the novel agar assay system was valid for at least two filamentous fungi. In contrast to T. mentagrophytes, a new inhibition zone of conidium formation was observed outside of the growth inhibition zone in the Aspergillus dish. This was clearly shown by the white zone against the green conidium background. The conidium formation was inhibited by lower vapor concentration than the growth inhibition, since the white inhibitory diameter was larger than the transparent growth inhibitory diameter, as shown in Table 3. The white zone was also observed in the agar vapor and the vapor-inhibitory assays (data not shown). As reported earlier, the antisporulating effect of essential oil was observed only in the vapor state but not in the aqueous media, and was caused by suppression of the formation of conidiophores ${ }^{15)}$.

The results obtained in this study revealed

Table 3. Growth-inhibitory diameters of 10 major components of essential oils in the agar diffusion, agar vapor and agar vapor-inhibitory assays against $A$. fumigatus

\begin{tabular}{|c|c|c|c|c|c|}
\hline \multirow{2}{*}{ Function } & \multirow{2}{*}{ Oil component } & \multicolumn{4}{|c|}{ Inhibitory diameter (mm) } \\
\hline & & Diffusion assay & Vapor assay & Vapor-inhibitory assay & $\delta$ value \\
\hline Aldehyde & Citral $(5 \%)$ & $42 \pm 4(50 \pm 7) *$ & $56 \pm 4$ & $34 \pm 2$ & 38 \\
\hline Aldehyde & Perrilaldehyde $(5 \%)$ & $30 \pm 5(36 \pm 5)$ & $25 \pm 5$ & $25 \pm 1$ & 56 \\
\hline Phenol & Thymol $(5 \%)$ & $48 \pm 3(81 \pm 9)$ & $51 \pm 7$ & $29 \pm 1$ & 70 \\
\hline Alcohol & Linalool $(100 \%)$ & $43 \pm 5(51 \pm 8)$ & $62 \pm 7$ & $25 \pm 2$ & 82 \\
\hline Alcohol & Terpinen-4-ol (100\%) & $48 \pm 8(55 \pm 9)$ & $68 \pm 9$ & $27 \pm 2$ & 78 \\
\hline Alcohol & Carene alcohol $(100 \%)$ & $52 \pm 4(75 \pm 7)$ & $50 \pm 8$ & $30 \pm 2$ & 71 \\
\hline Ester & Linalyl acetate $(100 \%)$ & $10 \pm 0(13 \pm 2)$ & not detected & $21 \pm 0$ & \\
\hline Oxide & Carene oxide $(100 \%)$ & $49 \pm 4(60 \pm 7)$ & $53 \pm 7$ & $22 \pm 1$ & 96 \\
\hline Hydrocarbon & 3-Carene $(100 \%)$ & $35 \pm 3(46 \pm 8)$ & $37 \pm 6$ & $21 \pm 0$ & 100 \\
\hline Hydrocarbon & Limonene $(100 \%)$ & $33 \pm 2(55 \pm 8)$ & $35 \pm 4$ & $22 \pm 1$ & 92 \\
\hline
\end{tabular}

For the calculation of a delta value, see Table 1 footnote.

* Figure in parenthesis indicates an inhibitory diameter of the conidium formation 
that essential oils were specifically active against T. mentagrophytes. As judged from inhibitory diameters and concentrations of 24 essential oils (Table 1), cinnamon bark, lemongrass, perilla, oregano, thyme thymol, clove, palmarosa and geranium Bourbon were found to be the most potent. Melissa, citronella, rosewood, sandalwood, thyme geraniol, santolina, galbanum, nutmeg, coriander, thyme thujanol, lavender and tea tree oils showed moderate activity, while tansy, ravensara, frankincense and myrrh were weakest in activity.

Literature search on essential oils evaluated by agar diffusion assay against $T$. mentagrophytes revealed 5 papers testing oils of Ocimum sp. ${ }^{16)}$, Humulus lupulus ${ }^{17)}$ Jasonia sp. ${ }^{18)}$, Cymbopogen citrates $^{19)}$, and Agastache rugosa ${ }^{20)}$, and no systematic study using a large number of oils has been published. Since most of the oils reported were not included in our study, it was difficult to compare our data with those of other workers. This was the first to study the activity of many oils of wide structural variety against T. mentagrophytes. Griffin et al. ${ }^{9)}$ and Porter ${ }^{21)}$ mentioned that the amount of oil in the agar diffusion assay was reduced by extensive evaporation from the paper disc and from agar during incubation. None of these authors indicated the contribution of the vapor activity in the diffusion assay.

Our study clearly indicated that the vapor activity of essential oils contributed considerably to the inhibitory diameter, and suggested that the agar diffusion assay was valuable for the determination of their antimicrobial activity in which the poor diffusibility of oil was compensated by the high volatility to exhibit a large inhibition zone. Since some of the essential oils and their constituents showed potent vapor activity against T. mentagrophytes and A. fumigatus, these oils and constituents might be applied for the vapor therapy against fungal infection or for disinfection of indoor molds, provided that the antifungal spectrum, mode of vapor action and safety assessment were elucidated.

\section{References}

1) Jollois R: L'aromatherapie exactement, Nouvelles editions Roger Jollois, Paris, France, 1996.

2) Nelson RRS: In vitro activities of five plant essential oils against methicillin-resistant Staphylococcus aureus and vancomycin-resistant Enterococcus faecium. J Antimicrob Chemother 40: 305-306, 1997.

3) Inouye S, Yamaguchi H, Takizawa T: Screening of the antibacterial effects of a variety of essential oils on respiratory tract pathogens, using a modified dilution assay method. J Infect Chemother 7: 251-254, 2001.

4) Vazquez JA, Zawawi AA: Efficacy of alcoholbased and alcohol-free melaleuca oral solution for the treatment of fluconazole-refractory oropharyngeal candidiasis in patients with AIDS. HIV Clin Trials 3: 379-385, 2002.

5) Mondello F, De Bernardis F, Girolamo A, Salvatore $\mathrm{G}$, Cassone $\mathrm{A}$ : In vitro and in vivo activity of tea tree oil against azole-susceptible and -resistant human pathogenic yeasts. J Antimicrob Chemother 51: 1223-1229, 2003.

6) Kalemba D, Kunicka A: Antimicrobial and antifungal properties of essential oils. Curr Med Chem 10: 813-829, 2003.

7) Chao SC, Young DG, Craig CJ: Screening for inhibitory activity of essential oils on selected bacteria, fungi and viruses. J Essent Oil Res 12: 639-649, 2000.

8) Kubo A, Lunde CS, Kubo I: Antimicrobial activity of the olive oil flavor compounds. J Agric Food Chem 43: 1629-1633, 1995.

9) Griffin SG, Markham JL, Leach DN: An agar dilution method for the determination of the minimum inhibitory concentration of essential oils. J Essent Oil Res 12: 249-255, 2000.

10) Inouye $S$, Tsuruoka $T$, Uchida $K$, Yamaguchi $\mathrm{H}$ : Effect of sealing and Tween-80 on the antifungal susceptibility testing of essential oils. Microbiol Immunol 45: 201-208, 2001.

11) Inouye $S$, Takizawa $T$, Yamaguchi $H$ : Antibacterial activity of essential oils and their major constituents against respiratory tract pathogens by gaseous contact. J Antimicrob Chemother 47: 565-573, 2001.

12) Inouye $S$, Tsuruoka $T$, Watanabe $M$, Takeo $K$, Akao M, Nishiyama Y, Yamaguchi H: Inhibitory effect of essential oils on apical growth of Aspergillus fumigatus by vapour contact. Mycoses 43: 17-23, 2000.

13) Inouye S, Uchida K, Yamaguchi H: In-vitro and in-vivo anti-Trichophyton activity of essential oils by vapour contact. Mycoses 44: 99-107, 2001.

14) Maruzzella JC, Sicurella NA: Antibacterial activity of essential oil vapors. J Amer Pharmaceut Assoc Sci Edit 49: 692-694, 1958.

15) Inouye $S$, Watanabe $M$, Nishiyama $Y$, Takeo $K$, Akao M, Yamaguchi $\mathrm{H}$ : Antisporulating and respiration-inhibitory effects of essential oils on filamentous fungi. Mycoses 41: 403-410, 1998.

16) Janssen AM, Scheffer JJ, Ntezurubanza L, Baerheim Svendsen A: Antimicrobial activities of some Ocimum species grown in Ruwanda. J Ethnopharmacol 26: 57-63, 1989.

17) Langezaal CR, Chandra A, Scheffer JJ: Antimicrobial screening of essential oils and extracts of some Humulus lupulus L. cultivars. Pharm Weekbl Sci 14: 353-356, 1992.

18) Hammerschmidt FJ, Clark AM, Soliman FM, El- 
Kashoury EA, Abd El-Kawyy MM, El-Fishawy AM: Chemical composition and antimicrobial activity of essential oils of Jasonia candicans and J. montana. Planta Med, 59: 68-70, 1993.

19) Wannisorn B, Jarikasem S, Soontorntanasart $T$ : Antifungal activity of lemon grass oil and lemon grass oil cream. Phytother Res 10: 551554, 1996.
20) Shin S: Essential oil compounds from Agastache rugosa as antifungal agents against Trichophyton species. Arch Pharm Res 27: 295-299, 2004.

21) Porter NG: What test to measure the antimicrobial activity of your oil. $6^{\text {th }}$ International Lavender Conference, Abstract of papers, p.58, Waga Waga, Australia, 2001. 